\title{
GROWTH OF THE ECTOMYCORRHIZAL FUNGUS PISOLITHUS MICROCARPUS IN DIFFERENT NUTRITIONAL CONDITIONS
}

\author{
Márcio José Rossi*, Vetúria L. Oliveira \\ Departamento de Microbiologia, Imunologia e Parasitologia, Centro de Ciências Biológicas, Universidade Federal de Santa \\ Catarina, Florianópolis, SC, Brasil.
}

Submitted: November 13, 2009; Returned to authors for corrections: September 29, 2010; Approved: January 13, 2011.

\begin{abstract}
The most important plant species employed in reforestation programs depend on ectomycorrhizal fungi for their establishment and growth. The exploitation of this symbiosis to improve forest productivity requires fungal inoculants in a large scale level. To develop such a technology it is necessary to define the optimal composition of the culture medium for each fungus. With these objectives in mind, the effect of the composition of the culture medium on biomass production of the ectomycorrhizal fungus Pisolithus microcarpus (isolate UFSC-Pt116) was studied. The original composition of two culture media, already employed for cultivation of ectomycorrhizal fungi, was submitted to several variations with the $\mathrm{C} / \mathrm{N}$ ratio as the main variable. A variation of the Pridham-Gottlieb medium was the most efficient for the production of biomass. Therefore, it was submitted to a factorial assay where glucose, peptone and yeast extract components were the factors analyzed. Results showed that the glucose concentration may be increased up to $40 \%$ in order to promote higher biomass production. Peptone had a positive effect on this variable, whereas yeast extract promoted a deleterious effect. These results indicate that it is advisable to eliminate yeast extract from the medium and replace it with peptone prior to use.
\end{abstract}

Key words: Pisolithus microcarpus, culture media, C/N ratio, submerged cultivation.

\section{INTRODUCTION}

The ectomycorrhizal symbiosis is an important factor for the survival and growth of many forest trees. The predominance of positive effects of this symbiosis in the establishment and growth of forest plants demonstrates that ectomycorrhizal inoculation is a valuable tool for plant production in forestry $(7,19)$. Species of the ectomycorrhizal genus Pisolithus are among those most studied concerning the effects on plant growth. The species of that genus are relatively easy to cultivate in laboratory and are able to adapt to many soil and environmental conditions, hence their frequent utilization in the inoculation of seedlings in reforestation programs $(13,14)$. 
The capacity of the ectomycorrhizal fungi (ECM) to associate with plants under natural conditions is a sign that the fungi derive carbonate substances from the plant host, which are essential for the growth of those fungi (19). In culture, these fungi require vitamins and sugars as growth factors. Many isolates are able to metabolize several carbon sources such as cellulose, maltose, trehalose and sucrose. However, Smith (18) found that glucose is the best assimilated sugar by Pisolithus tinctorius.

Most ECM can metabolize inorganic sources of nitrogen, $\mathrm{NH}_{4}{ }^{+}$or $\mathrm{NO}_{3}{ }^{-}$, the main source being the ammonium, because enzymes involved in its assimilation are present (4). It seems that Pisolithus species can utilize both ammonium and nitrate (18). Several authors have observed that some isolates of this genus are also able to utilize organic $\mathrm{N}$, although this ability has shown significant variation between species and isolates $(2$, $5,6,20)$. The capacity of an ectomycorrhizal fungus to obtain $\mathrm{N}$ directly from proteins is an important trait since this is the most abundant form of $\mathrm{N}$ available in temperate forest soils due to the low mineralization rates in these ecosystems (1). However, the capacity to utilize organic $\mathrm{N}$ in culture does not necessarily imply that the microorganism is able to do the same in natural conditions, where proteins may be linked to complex chemical compounds such as polyphenols.

The balance between carbon and organic nitrogen sources may also contribute to controlling the $\mathrm{pH}$ and hence to increasing productivity of the culture. Smith (18) optimized the biomass production of $P$. tinctorius in Modified MelinNorkrans (MMN) medium, developed by Marx (12), with an equimolar solution of citric acid and calcium citrate ( $\mathrm{pH} 5.4$ ) before sterilization. The Pridham-Gottlieb (PG) medium, used by Litchfield and Arthur (11) and Kuek (10) to cultivate $P$. tinctorius, is self-buffered by the presence of $\mathrm{KH}_{2} \mathrm{PO}_{4}$ and $\mathrm{K}_{2} \mathrm{HPO}_{4}$. In this medium, organic components such as peptone and yeast extract also contribute to control the $\mathrm{pH}$. Rossi et al. (17) obtained an expressive biomass production by Pisolithus microcarpus through modifications of this medium in an airlift bioreactor.

The inoculant production of ectomycorrhizal fungi demands that studies have to be undertaken to determine the nutritional requirements of these organisms before their massive cultivation in bioreactors and inoculation in forest plants take place. Another important factor to be studied concerns the maximum biomass concentration in the bioreactor in order to establish the initial level of nutrients to achieve such production. This depends on the fungus morphology during growth and on the hydrodynamic and oxygen transfer in the bioreactor system (16). Most studies on cultivation of ECM were performed in small flask scale, and only very few involved large scale inoculant production. In order to help the establishment of inoculant production methods, this study aims to test some modifications of $\mathrm{MMN}$ and $\mathrm{PG}$ media for the cultivation of the ectomycorrhizal fungus Pisolithus microcarpus, one of the ectomycorrhizal fungi frequently recorded in Eucalyptus plantations in southern Brazil (8).

\section{MATERIAL AND METHODS}

\section{Fungal isolate}

The ectomycorrhizal fungus Pisolithus microcarpus (Cooke and Massee) G. Cunn., isolate UFSC-Pt116, was employed in this study. This fungus was isolated from Eucalyptus dunnii plantations in the State of Santa Catarina, southern Brazil, and is kept in the ectomycorrhizal fungi culture collection at the "Laboratório de Ectomicorrizas" at the "Universidade Federal de Santa Catarina", Florianópolis, SC, Brazil. The isolate is maintained in solid MMN. The cultures are stored at $25 \pm 1{ }^{\circ} \mathrm{C}$, and transferred to fresh medium every two months.

\section{Culture media}

Modifications of two culture media were utilized as basal media. These media were MMN (modified Melin-Norkrans) (12), and Pridham-Gottlieb modified by Kuek (10), which will 
be called PGK hereafter. The MMN medium presented the following composition $\left(\mathrm{g} . \mathrm{L}^{-1}\right)$ : glucose 10.0; malt extract 3.0; $\mathrm{CaCl}_{2}$ 0.05; $\mathrm{NaCl}$ 0.025; $\left(\mathrm{NH}_{4}\right)_{2} \mathrm{PO}_{4} \quad 0.25 ; \mathrm{KH}_{2} \mathrm{PO}_{4} \quad 0.50$; $\mathrm{MgSO}_{4} .7 \mathrm{H}_{2} \mathrm{O} 0.15$; and thiamine- $\mathrm{HCl} 100 \mu \mathrm{g} . \mathrm{L}^{-1}$ and $1.2 \mathrm{~mL}$ of $\mathrm{FeCl}_{3}\left(1 \%\right.$, w/V). The PGK medium contained (g.L $\left.{ }^{-1}\right)$ : glucose 10.0; peptone 3.33; yeast extract $0.67 ; \mathrm{NH}_{4} \mathrm{NO}_{3} 1.0$; $\mathrm{KH}_{2} \mathrm{PO}_{4} \quad 0.264 ; \quad \mathrm{K}_{2} \mathrm{HPO}_{4} \quad 0.628 ; \quad \mathrm{MgSO}_{4} .7 \mathrm{H}_{2} \mathrm{O} \quad 0.33$; $\mathrm{CuSO}_{4} .5 \mathrm{H}_{2} \mathrm{O} \quad 0.0021 ; \mathrm{MnCl}_{2} \cdot 4 \mathrm{H}_{2} \mathrm{O} \quad 0.0006 ; \mathrm{ZnSO}_{4} .7 \mathrm{H}_{2} \mathrm{O}$ 0.0005; and $\mathrm{FeSO}_{4} .7 \mathrm{H}_{2} \mathrm{O} 0.0004$. In both media, both addition of glucose and $\mathrm{pH}$ adjustment to 5.8 were performed before sterilization.

\section{Inoculation procedures and culture conditions}

Mycelia plugs with $7 \mathrm{~mm}$-diameter were obtained from 20 to 25-day old cultures in MMN-agar in Petri dishes. These plugs were previously tested for viability and purity in fresh culture medium in Petri dishes for 2 days of incubation. Five disks were employed to inoculate $30 \mathrm{~mL}$ of liquid medium (MMN or PG) in $250 \mathrm{~mL}$ flasks. Medium had been previously sterilized at $121^{\circ} \mathrm{C}$ for $20 \mathrm{~min}$. The cultures were incubated at $25 \pm 1^{\circ} \mathrm{C}$ in the dark with 3 replicates per treatment.

\section{Analytical procedures}

The amount of residual glucose was determined through an enzymatic technique called GOD (glucose oxidase), by employing the reagent EnzColor from Biodiagnóstica Indústria Química Clínica Ltda. Biomass was estimated after drying the mycelium at $75{ }^{\circ} \mathrm{C}$ for a period of 48 hours, and the $\mathrm{pH}$ was determined conventionally. All samples represented the total content of each flask.

\section{Effect of the medium composition on the growth of Pisolithus microcarpus}

Different modifications on the composition of the culture media (Table 1) were tested in order to obtain preliminary information about the nutritional requirements of the fungus. Two assays were performed and the fungus was cultivated in the different media and incubated as described above.

Table 1. $\mathrm{C} / \mathrm{N}$ ratio on the different modifications of Melin-Norkrans and Pridham-Gotllieb media.

\begin{tabular}{|c|c|c|}
\hline Culture media & $\mathbf{C} / \mathbf{N}$ & Description \\
\hline $\mathrm{MMN}$ & $50 / 1$ & Medium as modified by Marx (1969) \\
\hline MMN +micro & $50 / 1$ & MMN supplemented with 2 mL.L $\mathrm{L}^{-1}$ of a micronutrient solution ${ }^{\mathrm{a}}$ \\
\hline $\mathrm{MMN}+3 \mathrm{YE}$ & $5,6 / 1$ & MMN supplemented with 3.0 g.L $\mathrm{L}^{-1}$ of yeast extract $\mathrm{b}^{\mathrm{b}}$ \\
\hline $\mathrm{MMN}+3 \mathrm{YE}-3 \mathrm{ME}$ & $4,5 / 1$ & MMN with the replacement of malt extract ${ }^{\mathrm{c}}$ by yeast extract \\
\hline $\mathrm{MMN}+1 \mathrm{YE}+$ micro & $14 / 1$ & $\begin{array}{l}\text { MMN supplemented with } 1.0 \mathrm{~g} \cdot \mathrm{L}^{-1} \text { of yeast extract and } 2 \mathrm{~mL} . \mathrm{L}^{-1} \\
\text { of a micronutrient solution }\end{array}$ \\
\hline $\mathrm{MMN} \mathrm{A} / \mathrm{C}$ & $50 / 1$ & $\begin{array}{l}\text { MMN supplemented with } 40 \mathrm{~mL} \cdot \mathrm{L}^{-1} \text { of citric acid/sodium citrate } \\
0.1 \mathrm{M} \text { as a } \mathrm{pH} \text { buffer }\end{array}$ \\
\hline $\mathrm{MMN} \mathrm{A} / \mathrm{C}+\mathrm{N}$ & $20 / 1$ & MMM A/C supplemented with $0.62 \mathrm{~g} . \mathrm{L}^{-1}$ of $\left(\mathrm{NH}_{4}\right)_{2} \mathrm{HPO}_{4}$ \\
\hline PGK & $5 / 1$ & Medium as modified by Kuek (1996) \\
\hline PGKM & $7 / 1$ & $\begin{array}{l}\text { PGK medium supplemented with } 2 \text { g.. } \mathrm{L}^{-1} \text { of peptone }{ }^{\mathrm{d}}, 0.5 \mathrm{~g} . \mathrm{L}^{-1} \text { of } \\
\text { yeast extract and } 0.8 \mathrm{~g} . \mathrm{L}^{-1} \text { of } \mathrm{NH}_{4} \mathrm{NO}_{3}\end{array}$ \\
\hline
\end{tabular}


In the first experiment out of six formulations tested, five were modifications of the MMN medium. In the second assay, two other modifications of the MMN medium and one of the PGK represented the three treatments. Residual glucose, biomass and $\mathrm{pH}$ of the culture media were measured at the end of the cultivation period, which lasted 14 days. In the second assay, there were five treatments represented by three formulations of the MMN medium and two of the PGK medium. The biomass yield $\left(\mathrm{Y}_{\mathrm{X} / \mathrm{S}}\right)$ was calculated using the following equation:

$$
\mathrm{Y}_{\mathrm{X} / \mathrm{S}}=\frac{\mathrm{X}-\mathrm{X}_{0}}{\mathrm{~S}_{0}-\mathrm{S}}
$$

where $\left(\mathrm{g} \cdot \mathrm{L}^{-1}\right): \quad \mathrm{X}_{0}=$ initial biomass; $\mathrm{S}_{0}=$ initial glucose; $\mathrm{X}=$ final biomass; $\mathrm{S}=$ final glucose.

Biomass productivity $\left(\mathrm{P}_{\mathrm{x}}\right)$, in $\mathrm{g} \cdot \mathrm{L}^{-1} \cdot \mathrm{day}^{-1}$, was calculated by the equation:

$$
\mathrm{P}_{\mathrm{X}}=\frac{\mathrm{X}-\mathrm{X}_{0}}{\mathrm{t}}
$$

where: $\mathrm{t}=$ time of cultivation (days)
The medium that promoted maximum biomass production in the preliminary assays was employed in the next study in order to determine the minimal concentration of the more expensive nutrients to allow for maximum growth. For that purpose, a complete factorial design $2^{3}$, including 4 central points, was employed where the factors (variables) were: glucose (GL), peptone (PP) and yeast extract (YE). The relation between the biomass produced and substrate (glucose) was used to obtain the values of $y\left(g_{\text {biom }} \cdot g_{\text {gluc }}{ }^{-1}\right)$ according to the equation below:

$$
\mathrm{y}=\frac{\text { biomass produced }}{\text { initial content of glucose }}
$$

The conversion defined by Equation 3 differs from the classical definition of $\mathrm{Y}_{\mathrm{X} / \mathrm{S}}$ because it considers the entire amount of glucose present in the culture medium instead of only the amount used by the fungus. To establish the algorithm to calculate the effects, the actual levels of the factors were replaced by their respective encoded values $(+1$ and -1$)$ (3) as shown in Table 2.

\begin{tabular}{|c|c|c|c|c|c|c|c|}
\hline \multirow[t]{2}{*}{ Run } & \multicolumn{3}{|c|}{ Actual value of factors (g.L $\left.\mathrm{L}^{-1}\right)$} & \multicolumn{3}{|c|}{ Encoded factors } & \multirow{2}{*}{$\begin{array}{c}\mathbf{y} \\
\left(\text { g }_{\text {biom}} \cdot \mathrm{g}_{\text {gluc }}{ }^{-1}\right)\end{array}$} \\
\hline & GL & $\mathbf{P P}$ & $\mathbf{Y E}$ & $\mathbf{x}_{1}$ & $\mathbf{x}_{2}$ & $\mathbf{x}_{3}$ & \\
\hline 1 & 10.0 & 1.70 & 0.40 & -1 & -1 & -1 & 0.443 \\
\hline 2 & 14.0 & 1.70 & 0.40 & +1 & -1 & -1 & 0.414 \\
\hline 3 & 10.0 & 3.30 & 0.40 & -1 & +1 & -1 & 0.497 \\
\hline 4 & 14.0 & 3.30 & 0.40 & +1 & +1 & -1 & 0.455 \\
\hline 5 & 10.0 & 1.70 & 1.00 & -1 & -1 & +1 & 0.413 \\
\hline 6 & 14.0 & 1.70 & 1.00 & +1 & -1 & +1 & 0.419 \\
\hline 7 & 10.0 & 3.30 & 1.00 & -1 & +1 & +1 & 0.432 \\
\hline 8 & 14.0 & 3.30 & 1.00 & +1 & +1 & +1 & 0.418 \\
\hline $9 \mathrm{C}$ & 12.0 & 2.50 & 0.70 & 0 & 0 & 0 & 0.425 \\
\hline $10 \mathrm{C}$ & 12.0 & 2.50 & 0.70 & 0 & 0 & 0 & 0.420 \\
\hline $11 \mathrm{C}$ & 12.0 & 2.50 & 0.70 & 0 & 0 & 0 & 0.450 \\
\hline $12 \mathrm{C}$ & 12.0 & 2.50 & 0.70 & 0 & 0 & 0 & 0.429 \\
\hline
\end{tabular}

Table 2. Real and encoded levels of the factors studied (glucose, peptone and yeast extract) and the conversion of substrate (glucose) into biomass (y), according to a factorial design.

$\mathrm{GL}=$ glucose $; \mathrm{PP}=$ peptone; $\mathrm{YE}=$ yeast extract 
Data for biomass and biomass yield were submitted to analysis of variance (ANOVA) and means compared using the Fisher's LSD test $(p \leq 0.05)$. The statistical significance of the model to explain the effects of the factors was obtained by ANOVA. This analysis included Fisher's $F$-test $(p \leq 0.05)$ and its associated coefficient of determination $R^{2}$. All statistical analyses were performed using the STATISTICA $^{\circledR} 6.0$ software (StatSoft Inc., Tulsa, Oklahoma, USA).

\section{RESULTS AND DISCUSSION}

\section{Effect of the medium composition on the growth of}

\section{Pisolithus microcarpus}

During the first 10 days of cultivation, no treatment was able to promote glucose exhaustion. After 25 days, the media in the majority of treatments still presented more than $10 \%$ of residual glucose (Figure 1). However, the $\mathrm{MMN} A / \mathrm{C}+\mathrm{N}$ treatment promoted the highest yield $\left(\mathrm{Y}_{\mathrm{X} / \mathrm{S}}\right)$ (Figure 2$)$, with expressive biomass production of $5.0 \mathrm{~g} . \mathrm{L}^{-1}$ and productivity of 0.20 g. $\mathrm{L}^{-1} \cdot$ day $^{-1}$. The second highest value of biomass was obtained with MMN A/C treatment, with 0.18 g.L L $^{-1}$ day ${ }^{-1}$. These results seem to be related to the properties of the citric acid, which acts as a $\mathrm{pH}$ buffer under acid conditions, or as a chelating agent of metallic ions in the culture medium. It was observed that the $\mathrm{pH}$ of the medium stabilized at 3.15, which is the pKa of the citric acid. Besides these effects, it must also be considered that this is one of the acids in the Krebs cycle and may also be consumed by the fungus during the energy producing metabolism.

The main difference between treatments $\mathrm{MMN} A / \mathrm{C}+\mathrm{N}$ and $\mathrm{MMN} \mathrm{A} / \mathrm{C}$ resided in the amount of nitrogen. Results indicate that the $\mathrm{C} / \mathrm{N}$ ratio of $20 / 1$ in the former is more advantageous for the growth of the fungus. Smith (18) also observed that a $\mathrm{C} / \mathrm{N}$ ratio of $20 / 1$ resulted in better biomass production by the fungus $P$. tinctorius in MMN medium.

Addition of micronutrients to the culture medium (MMN + micro) contributed to improving biomass production during the first 10 days of cultivation (Figure 1a) when compared to the control treatment (original MMN). However, after 25 days (Figure 1b), the biomass produced by this treatment was inferior to that of the control. The treatment with the addition of yeast extract (YE) and those where malt extract (ME) was replaced by $\mathrm{YE}(\mathrm{MMN}+3 \mathrm{YE}$ and $\mathrm{MMN}+3 \mathrm{YE}-3 \mathrm{ME})$ also presented a lower biomass yield than the control (Figure 2), inspite of the buffering effect of the proteins present in the yeast extract. In the medium supplemented with 3 g.L. $\mathrm{L}^{-1}$ of YE (MMN +3YE) (Figure 1b), the low biomass production indicates a negative effect of this compound on the growth of the fungus.
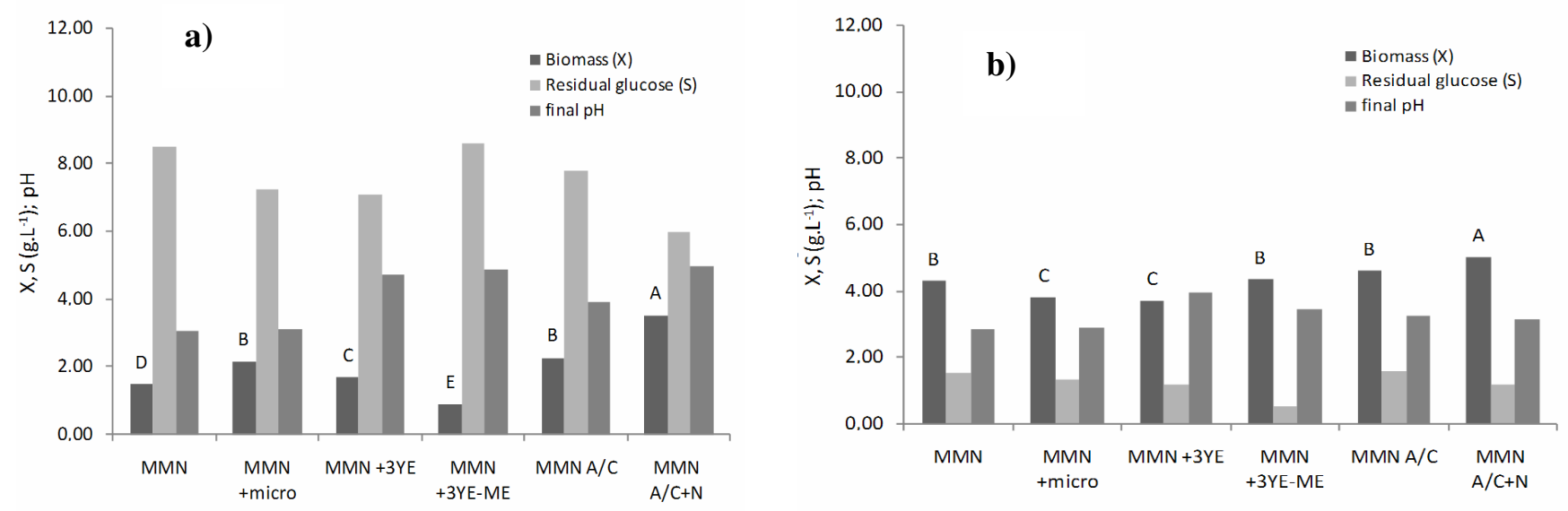

Figure 1. Biomass, residual glucose and $\mathrm{pH}$ after 10 days (a) and 25 days (b) of static cultivation of the ectomycorrhizal fungus Pisolithus microcarpus, at $25 \pm 1{ }^{\circ} \mathrm{C}$, under different nutritional conditions. Values of biomass indicated by different letters are significantly different according to Fisher's LSD test $(p \leq 0.05)$. 


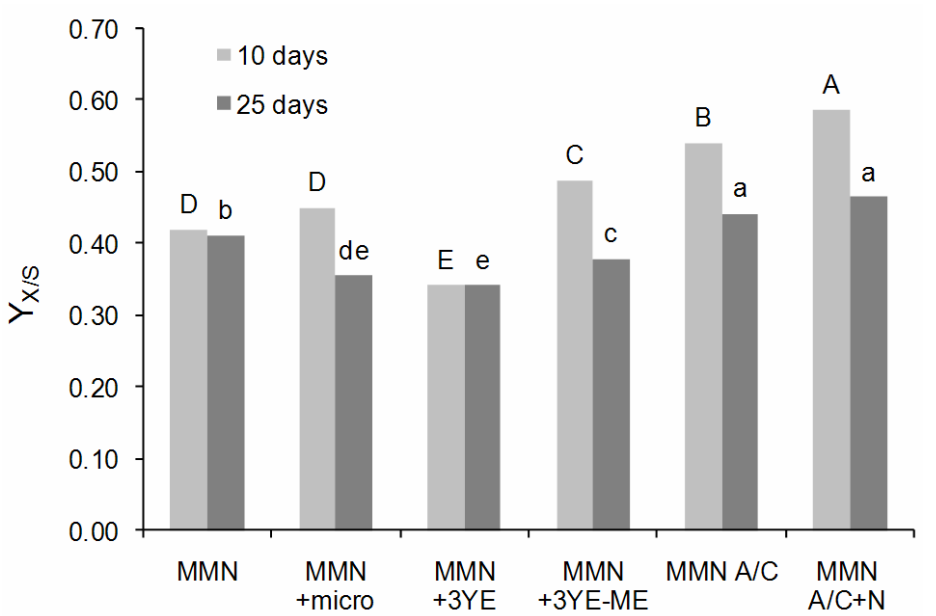

Figure 2. Biomass yield $\left(\mathrm{Y}_{\mathrm{X} / \mathrm{S}}\right)$ after 10 and 25 days of a static cultivation of the ectomycorrhizal fungus Pisolithus microcarpus in different modifications of the MMN culture medium at $25^{\circ} \mathrm{C}$. Values indicated by different letters are significantly different according to Fisher's LSD test $(p \leq 0.05)$.

Comparing the results after 10 days of cultivation (Figure 1a) to those after 25 days (Figure 1b), it is possible to notice that all treatments containing $\mathrm{YE}$ presented lower biomass production after 10 days. However, after this period there was a recovery of the production rate, which suggests an adjustment of the fungus to the medium conditions. A lag phase is not recommended because it represents a longer cultivation period and higher nutrient requirements, contributing to lower biomass yield $(0.34$ in the treatment $\mathrm{MMN}+3 \mathrm{YE}, 0.38$ in the treatment $\mathrm{MMN}+3 \mathrm{YE}-\mathrm{ME}$, and 0.41 in the control MMN) (Figure 2). Moreover, treatments containing YE presented a dark color at the end of the cultivation, indicating intense secondary metabolism. In this case, it shows a negative feature of these treatments because it may contribute to loss of biomass yield.

We suggest that the long term cultivation and the presence of residual glucose in this assay impose high risk of contamination of the inoculant. Moreover, residual glucose may also indicate the existence of a growth limiting factor, which could inhibit its complete utilization. For these reasons, a second assay was performed, in which the amount of yeast extract in the MMN medium was reduced to only $1.0 \mathrm{~g} . \mathrm{L}^{-1}$, according to Pradella et al. (15).

Among the new formulations studied, the PGK medium and its variation (PGKM) were those that promoted glucose exhaustion by the fungus (Figure 3), reaching a final $\mathrm{pH}$ of 2.7. Cultivation time length was 12 days, which is considered enough for the total uptake of glucose from both media, and has ensured productivity of 0.50 g.L $\mathrm{L}^{-1} \cdot \mathrm{day}^{-1}$, higher than that observed in any other formulation based on MMN medium.

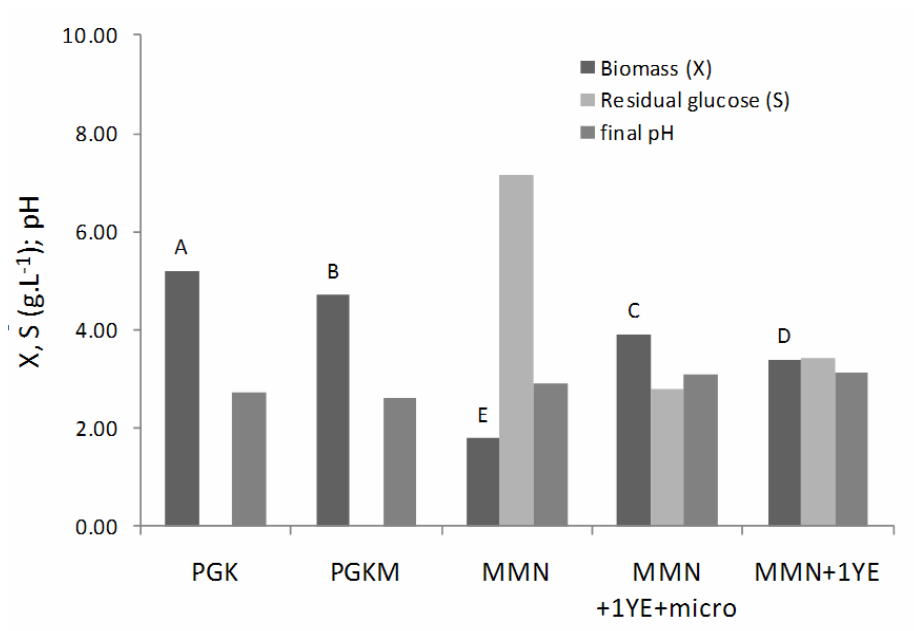

Figure 3. Biomass, residual glucose, and final $\mathrm{pH}$ after 12 days of static cultivation of the ectomycorrhizal fungus Pisolithus microcarpus, in different culture media, at $25 \pm 1^{\circ} \mathrm{C}$. Values indicated by different letters are significantly different according to Fisher's LSD test $(p \leq 0.05)$.

The addition of $1 \mathrm{~g} . \mathrm{L}^{-1}$ of yeast extract (YE) to the MMN $(\mathrm{MMN}+1 \mathrm{YE}+$ micro, and $\mathrm{MMN}+1 \mathrm{YE})$ increased biomass production when compared to the original MNM formulation (control). Values of $\mathrm{pH}$ after cultivation in these media $\left(\mathrm{pH}_{\mathrm{f}}\right)$ were higher than in any other treatment (Figure 3). This was possibly the result of a buffering effect of the yeast extract which contributed to higher biomass productivity. 
When ectomycorrhizal fungi are cultivated in culture systems without $\mathrm{pH}$ control, often the $\mathrm{pH}$ decreases reaching values close to 2.5 (17). The stabilization of the $\mathrm{pH}$ then takes place thank to a buffering effect of the phosphoric acid $(\mathrm{pKa}=$ 2.12). In the presence of this acid, $\mathrm{pH}$ values stay around $\mathrm{pH}=$ $\mathrm{pKa} \pm 1$ (9). Although the fungus may tolerate low $\mathrm{pH}$ conditions, it has to be maintained in the optimum range as much as possible in order to obtain high productivity. In conclusion, even if the addition of yeast extract has contributed to stabilizing the culture $\mathrm{pH}$, it was not possible to observe its role as a fungal growth promoting factor as suggested by Pradella et al. (15).

Several treatments promoted significant changes in the color of the media during the cultivation. Such changes are evidence of differences in terms of metabolite production, but they did not present a direct relationship with biomass production, even though the treatments presenting most intense visual pigmentation were also those with lower biomass values. We have also observed that pigmentation of the culturemedium may occur as a result of fungal growth itself. However, presence of pigmentation could indicate limitations inherent to growing conditions.

Thus, the MMN medium was considered unbalanced for cultivation of the fungus, hence not convenient for cultivation procedures whose goals are high biomass production. However, this medium seems to be appropriate for the maintenance of fungal cultures. Its high $\mathrm{C} / \mathrm{N}$ ratio and slower growth will contribute to reducing both the frequency of subculturing and the costs related to this process. On the other hand, the PGK medium showed high efficiency for biomass production of the ectomycorrhizal fungi, but further studies are necessary in order to improve its composition.

\section{Improvement of the culture medium through a factorial design}

The objective of this experiment was to study variations in the formulation of the PGK medium, in order to maintain high biomass productivity and, at the same time, to reduce the amount of certain ingredients considered to be expensive to a minimum. The ingredients that are employed in higher quantity in the medium are peptone (PP), yeast extract (YE) and glucose (GL), thus contributing to high costs. The concentration of glucose was increased by $40 \%$ to verify if there was any other limiting nutrient within this range (from 10 to 14 g.L ${ }^{-1}$ ) and if it was possible to increase yield. This increase was established taking into consideration the volume of medium available for fungal growth into the bioreactor.

Factors PP and YE, individually, promoted significant effects on substrate conversion (y). Factor GL and the interactions between the factors studied had no significant effect on this response. The Pareto chart, shown in Figure 4, allows for a better understanding of this statement.

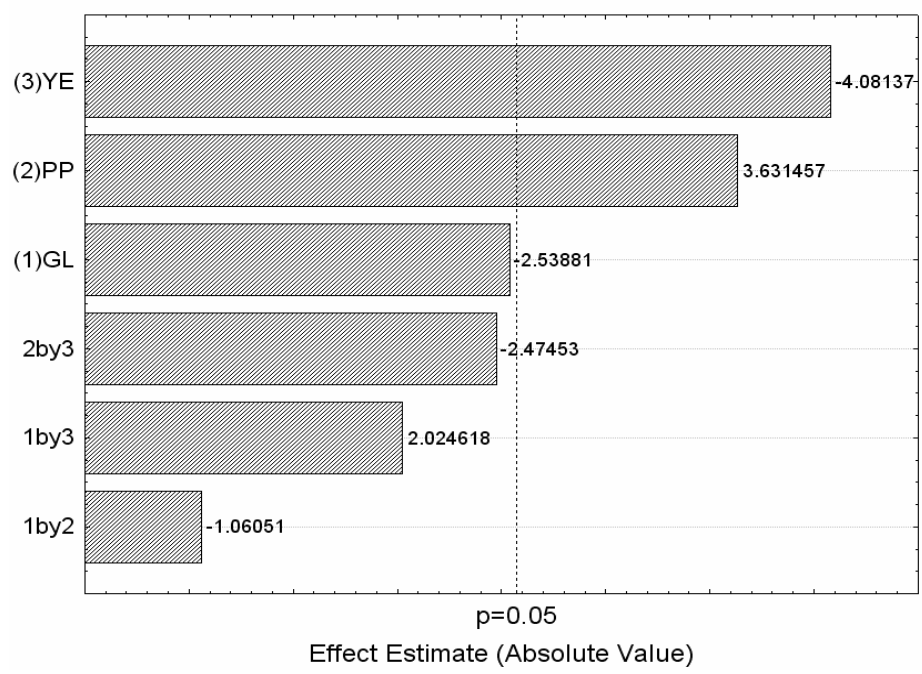

Figure 4. Pareto diagram illustrating the standardized effects $\left(t_{\text {calc }}\right)$ of peptone (PP), yeast extract (YE) and glucose (GL) on the substrate conversion (y) by the ectomycorrhizal fungus Pisolithus microcarpus. Values located on the right side of the broken line $\left(t_{\mathrm{tab}}\right)$ are those significantly different, according to the $t$-test $(p \leq 0.05)$.

Although the concentration of glucose (GL) presented no effect on substrate conversion (y), results showed that it is possible to increase biomass production by increasing the 
amount of this component up to $40 \%$ without reducing the conversion.

The addition of peptone (PP) has shown a favorable effect on substrate conversion (y) (Figure 4). Results indicated that the highest levels of peptone had a tendency to increase this conversion, and this effect was even higher when addition of peptone was combined to the smallest amounts of yeast extract (YE) (Table 2). Yeast extract has shown a negative effect on substrate conversion, which was also observed in the MMN medium in the formulations containing the highest amounts of yeast extract in the first 10 hours of cultivation (Figure 1a).

An ANOVA table for the regression model from Equation 4 is presented in Table 3, where the coefficient of determination was 0.905 and the calculated F-value $\left(\mathrm{F}_{\text {calc }}\right)$ was 1.6 times higher than the tabulated $\left(\mathrm{F}_{\mathrm{tab}}\right)$ value, indicating significant agreement between experimental results and the values estimated by the statistical model.

$$
\mathrm{Y}=0.435+0.014 \mathrm{PP}-0.016 \mathrm{YE}
$$

Table 3. ANOVA for the linear model of substrate (glucose) conversion (y).

\begin{tabular}{|c|c|c|c|c|c|}
\hline Source & of & Sum of squares & Degrees of & Mean squares & $\mathbf{F}_{\text {calc }}$ \\
\hline Regression & & 0.005766 & 6 & 0.000961 & 7.94 \\
\hline Error & & 0.000605 & 5 & 0.000121 & \\
\hline Total & & 0.006371 & 11 & & \\
\hline
\end{tabular}

$\mathrm{F}_{\text {tab }(6.5 ; 0.05)}=4.95 ; \mathrm{R}^{2}$, coefficient of determination $=0.905$

\section{CONCLUSIONS}

PGK medium is more efficient than MMN to promote biomass accumulation of the ectomycorrhizal fungus Pisolithus microcarpus. The presence of peptone in the former medium seems to be the factor which most contributed to that effect due to its rich nutritive composition and more efficient $\mathrm{pH}$ buffering. Yeast extract, on the other hand, may be eliminated or replaced by a higher amount of peptone, which will contribute to reducing media costs. Glucose concentration may be increased up to $40 \%$, promoting significant increase on biomass production without causing any limitation of other nutrients. This variation of the PGK medium may be potentially employed in studies of ectomycorrhizal inoculant production in bioreactor.

\section{ACKNOWLEDGEMENT}

The authors gratefully acknowledge Conselho Nacional de
Desenvolvimento Científico e Tecnológico (National Council for Scientific and Technological Development - CNPq) and Coordenação de Aperfeiçoamento de Pessoal de Nível Superior (Coordination for Improvement of Higher Level Personnel - CAPES) for their financial support.

\section{REFERENCES}

1. Abuzinadah, R.A.; Read, D.J. (1989). The role of proteins in the nitrogen nutrition of ectomycorrhizal plants. New. Phytol. 112 (1), 55-60.

2. Anderson, I.C.; Chambers, S.M.; Cairney, J.W.G. (1999). Intra- and interspecific variation in patterns of organic and inorganic nitrogen utilization by three Australian Pisolithus species. Mycol. Res. 103, 15791587.

3. Box, G.E.P; Hunter, W.G.; Hunter, J.S. (1978). Statistics for Experiments. John Wiley \& Sons, Toronto.

4. Cairney, J.W.G. (1999). Intra-specific physiological variation: implications for understanding functional diversity in ectomycorrhizal fungi. Mycorrhiza 9 (3), 125-135.

5. Cairney, J.W.G.; Chambers, S.M. (1997). Interactions between Pisolithus tinctorius and its hosts: a review of current knowledge. Mycorrhiza 7 (3), 117-131. 
6. Dickie, I.A.; Koide, R.T.; Stevens, C.M. (1998). Tissue density and growth response of ectomycorrhizal fungi to nitrogen source and concentration. Mycorrhiza 8 (3), 145-148.

7. Garbaye, J. (1990). Utilisation des mycorhizes en sylviculture. In: (Strullu, D.G., (ed.). Les mycorhizes des arbres et plantes cultivées), Lavoisier, Paris, France, p.197-248.

8. Giachini, A.J.; Oliveira, V.L.; Castellano, M.A.; Trappe, J.M. (2000) Ectomycorrhizal fungi in Eucalyptus and Pinus plantation in southern Brazil. Mycologia 92 (6), 1166-1177.

9. Jeffery, G.H.; Basset, J.; Mendham, J.; Denney, R.C. (1992). Vogel Análise Química Quantitativa. Editora LTC, Rio de Janeiro.

10. Kuek, C. (1996). Shake-flask culture of Laccaria laccata, an ectomycorrhizal basiodiomycete. Appl. Microbiol. Biotechnol. 45 (3), 319-326.

11. Litchfield, J.H.; Arthur, M.F. (1983). Growth of selected ectomycorrhizal fungi in aerated liquid culture. Develop. Ind. Microbiol. 24, 289-293.

12. Marx, D. H. (1969). The influence of ectotrophic mycorrhizal fungi on the resistance of pine roots to pathogenic infections. I. Antagonism of mycorrhizal fungi to root pathogenic fungi and soil bacteria. Phytopathology 59 (2), 153-163.

13. Marx, D.H.; Hatch, A.B.; Mendicino, J.F. (1977). High soil fertility decreases sucrose content and susceptibility of loblolly pine roots to ectomycorrhizal infection by Pisolithus tinctorius. Can. J. Bot. 55 (12),
1569-1574.

14. Marx, D.H.; Ruehle, J.L.; Kenney, D.S.; Cordell, C.E.; Riffle, J.W.; Molina, R.J.; Pawuk, W.H.; Navratil, S.; Tinus, R.W.; Goodwin. O.C. (1982). Commercial vegetative inoculum of Pisolithus tinctorius: inoculation techniques of development of ectomycorrhizae on containergrow tree seedlings. For. Sci. 28 (2), 273-400.

15. Pradella, J.G.C.; Zuccolo, M.; Lopes, S.A.R.; Oliveira, M.S. (1991). Pisolithus tinctorius vegetativa mycelia production: effects of nitrogen sources and cultivation in stirred tank fermenter. Rev. Microbiol. 22 (1), 7-11.

16. Rossi, M.J.; Furigo Jr., A.; Oliveira, V.L. (2007). Inoculant production of ectomycorrhizal fungi by solid and submerged fermentations. Food. Technol. Biotechnol. 45 (3), 277-286.

17. Rossi, M.J.; Souza, J.A.R.; Oliveira, V.L. (2002). Inoculum production of the ectomycorrhizal fungus Pisolithus microcarpus in an airlift bioreactor. Appl. Microbiol. Biotechnol. 59, 175-181.

18. Smith, R.A. (1982). Nutritional study of Pisolithus tinctorius. Mycologia 74 (1), 54-58.

19. Smith, S.E.; Read, D.J. (2008). Mycorrhizal symbiosis. Academic Press, London, New York.

20. Turnbull, M.H.; Goodall, R.; Stewart, G.R. (1995). The impact of mycorrhizal colonization upon nitrogen source utilization and metabolism in seedlings of Eucalyptus grandis Hill ex Maiden and Eucalyptus maculata Hook. Plant, Cell Environ. 18 (12), 1386-1394. 